\title{
TOWARDS THE ENHANCEMENT OF "MINOR" ARCHAEOLOGICAL HERITAGE
}

\author{
S. Morandi ${ }^{\text {a* }}$, M. Tremari ${ }^{\text {b }}$, A. Mandelli ${ }^{\mathrm{c}}$ \\ ${ }^{a}$ Studio Ar.Te. - Archeologia e Territorio; Università degli Studi di Sassari - simomorandi@y ahoo.com \\ ${ }^{\mathrm{b}}$ SAP - Società Archeologica s.r.l.; Museo Archeologico del Monte Barro - marco.tremari@ mail.com \\ c 3D Survey Group, ABC Department, Politecnico di Milano - alessandro.mandelli@polimi.it
}

\section{Commission II}

KEY WORDS : Emergency survey, Digital recording method, Close range photogrammetry, Virtual archaeology, AR and VR for CH

\section{ABSTRACT:}

The research is an analy sis of the recording, reconstruction and visualisation of the 3D data of a XVIII century watermill, identified in an emergency archaeological excavation during the construction of the mini-hydroelectric plant on the bank of the Adda river in the municipality of Pizzighettone (Cremona, Lombardy, Italy).

The work examines the use and the potentials of modern digital 3D modelling techniques applied to archaeological heritage aimed to increase the research, maintenance and presentation with interactive products. The use of three-dimensional models managed through AR (Augmented Reality) and VR (Virtual Reality) technologies with mobile devices gives several opportunities in the field of study and communication. It also improves on-site exploration of the landscape, enhancing the "minor" archaeological sites, daily subjected to numerous emergency works and facilitating the understanding of heritage sites.
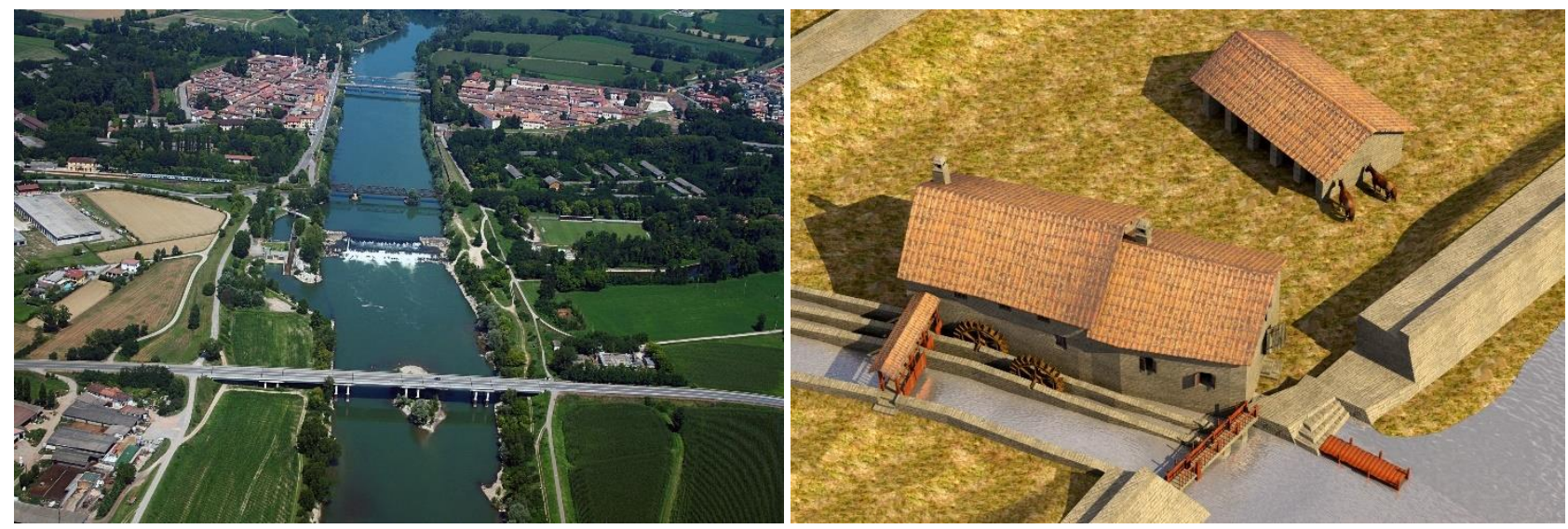

Figure 1. Left: aerial view of the site on the Adda river. Right: virtual reconstruction of the watermill on the left bank of Adda river.

\section{INTRODUCTION}

This research is an analysis of the recording, processing reconstruction and visualisation of the 3D data of a XVIII century watermill identified in an emergency archaeological excavation. The discovery, unearthed during the construction of the minihydroelectric plant, is located on the left bank of the Adda river in the municipality of Pizzighettone (Cremona, Lombardy, Italy).

The aim of the paper is to show the possibilities offered by digital technologies, mostly the digital photogrammetry and the virtual archaeology, to record and enhancing the "minor" archaeological sites that are daily subjected to numerous emergency surveys over the entire territory. Most of these interventions consistently produce vast amounts of data that are often confined to the archives and therefore not accessible to the public.
This work examines the use and the potentials of modern digital 3D modelling techniques applied to archaeological heritage to increase the divulgation and visualisation with interactive products. During fieldwork, the methodology and software employed were very sustainable, intended at surveying the site and considering the issues related to the disclosure of the acquired and processed archaeological data; in this way the collected information could be understood not only by scholars and professionals, but also by a larger audience.

The paper presents furthermore a case study, replicable in other emergency excavations sites, where archaeological remains, discovered as a result of urban works, are acquired and processed directly on the place of occurrence, non-invasively and through the use of low cost technologies.

\footnotetext{
* Corresponding author
} 


\section{THE SITE}

The subject of this study is the fortified post-medieval waterwheel mill brought to light during the excavation work for the new hydroelectric plant realized by Edison S.p.A. on the left bank of the Adda river in the municipality of Pizzighettone (Cremona, Lombardy, Italy).

The archaeological assistance was conducted between 2015 and 2016 within the construction of the future plant under the direction of the Lombardy's Superintendence for Archaeological Heritage, by the archaeological company Studio Ar.Te. It has highlighted some structures referring to remains of a fortified watermill, dated back to the XVIII century, connected to the channel structure for water convey ance of the Serio Morto river.

In the area of the Adda river, the first watermill was built in the Middle ages at the mouth of the tributary water course Serio Morto, taking advantage of the difference in height between the two rivers. Then in 1723, a new watermill, with two wheels, incorporated in the fortified Austrian walls of Pizzighettone, was built in place of the medieval structure. The construction was owned by the Countess Giovanna Lopez Aresini, as attested by a document concerning the request for the recompense of the town in the same period. The mill was indicated in the Teresian cadastre of 1732 as the only watermill with two wheels in the village of Pizzighettone, called or "Mulino Lopez" ("Mill Lopez" from the owner's name) or "Mulino degli Spalti" ("Mill of the Stands" due to its location inside the fortified walls) (Tansini et al., 2003).

The remains of the post-medieval watermill are located on the left bank of the Adda river to the share of $438 \mathrm{~m}$ a.s.l. and to the coordinates $45^{\circ} 10^{\prime} 54.80^{\prime \prime} \mathrm{N} 9^{\circ} 46^{\prime} 55.75^{\prime \prime} \mathrm{E}$ WGS84 $32 \mathrm{~N}$
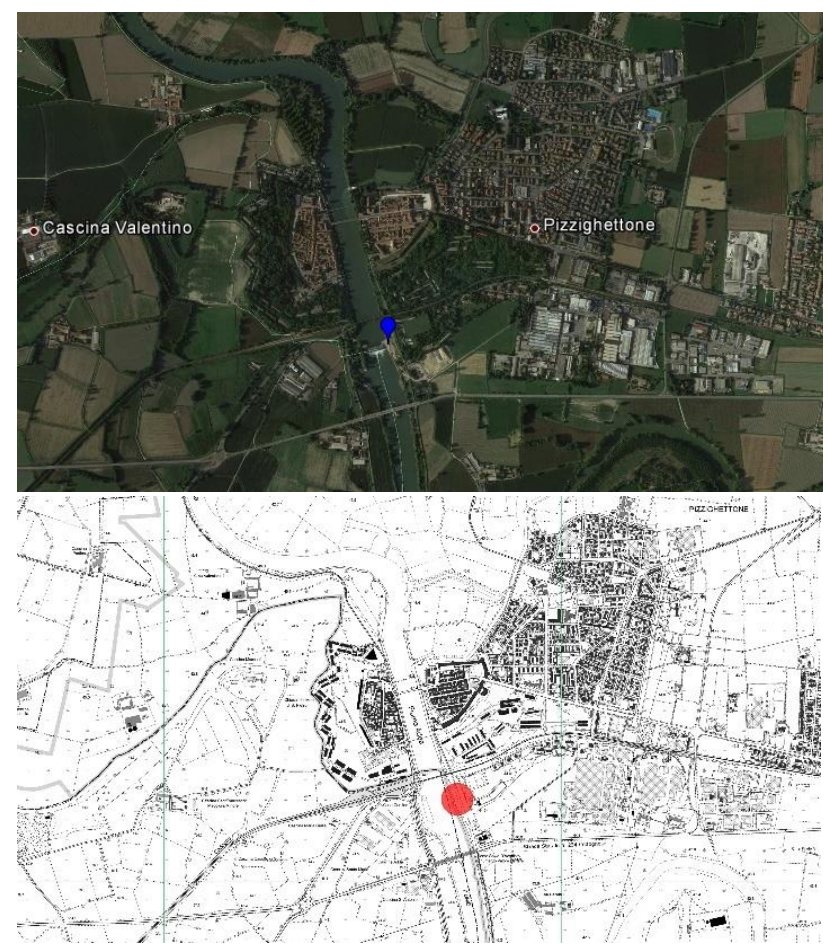

Figure 2. Above: view from Google Earth of the site on the Adda river. Below: site georeferenced on technical map.

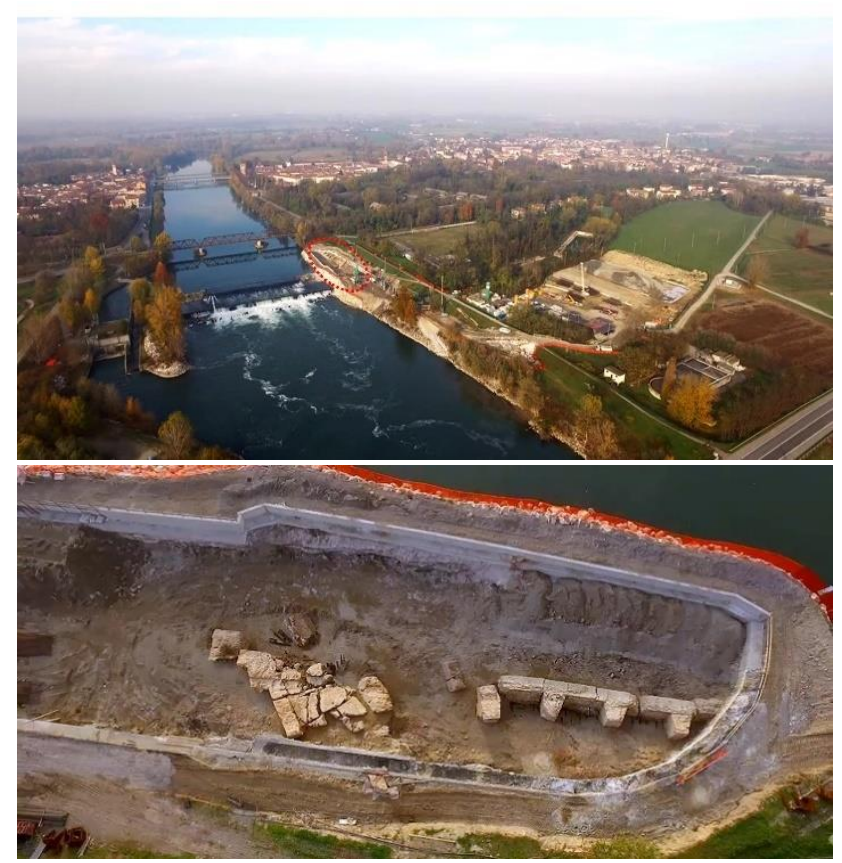

Figure 3. Above: aerial view of the area of the hydroelectric plant. Below: the archaeological structures on the Adda river.

The structure is poorly preserved, and consists of its northern part, including: the north wall, with the presence of two deep vertical "grooves" and a small portion of the southern wall with equal characteristics. Between the two wall structures, a floor was preserved, made of bricks placed in a herringbone pattem, and covered by a homogeneous mortar layer, characterized by the presence of a series of quadrangular and shallow holes and channels. These elements represent the parts to house all the necessary tools to control and use the water as the driving force of the mill; the absence of these mechanisms is due to their reuse in new mill built at the start of the XIX century.

Along the west front of the structures, wooden poles were found deeply driven into the ground with double function: to stabilize the massive structures of the mill and to contain the erosive action of the river. Moreover, the poles placed more externally had to be connected with a pier for mooring of boats that sailed on the river.

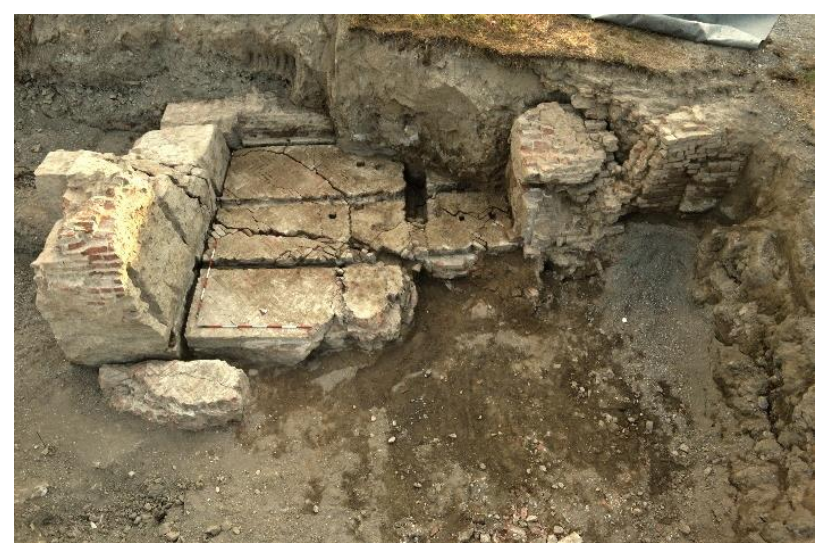

Figure 4. The remains of the watermill: details of the mill-pond and channels for the functioning of the waterwheels. 

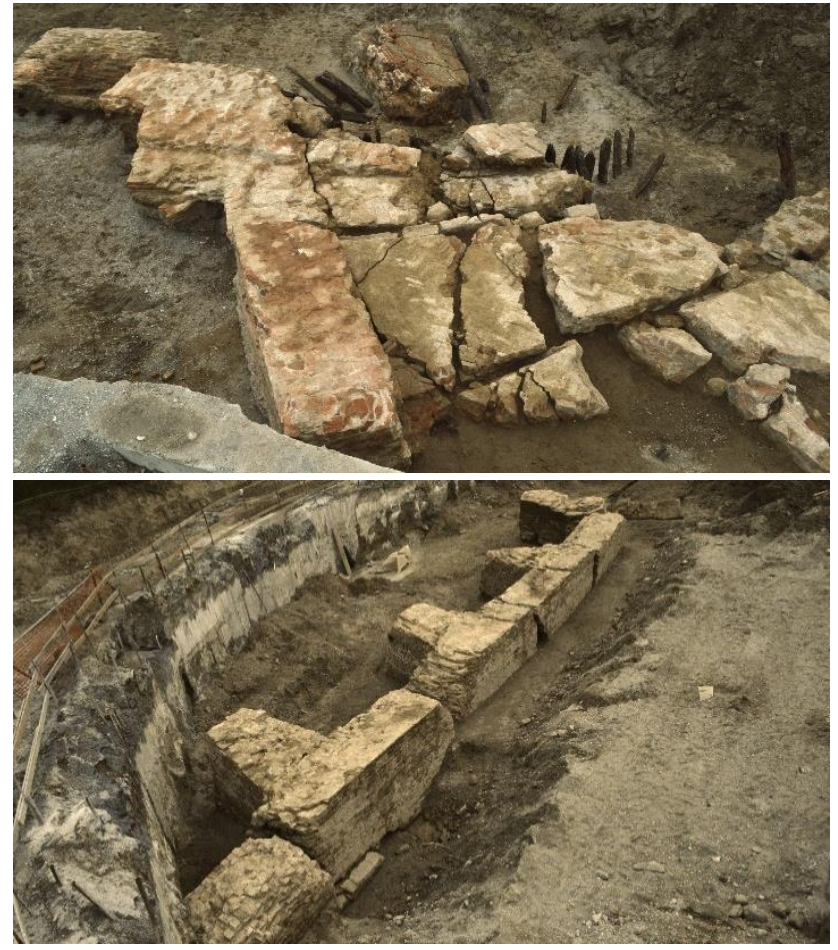

Figure 5. Above: the ruins of the watermill, details of the mil structure unearthed during the archaeological excavation. Below: details of the buttresses of the fortification wall.

There were also traces of four truncated cone shape buttresses, placed at a distance of about $4.5 \mathrm{~m}$ from each other, realized simultaneously and perfectly connected to the masonry structure. They were part of the fortification with bastions and stands restored and consolidated by the Austrians in the 1723. In this period new embankments were erected on the left shore of the Adda river, reinforced by walls with the buttresses up to the area where the new mill "Mulino degli Spalti" was built.

The skimpiness of the archaeological remains detected during fieldwork, made necessary their enhancement with a specific 3D reconstruction, based on the integration of the available resources: iconographic, archaeological and historical.

The watermill, already known by the Romans, had its maximum development in the medieval period. During the centuries, the ability of the man to produce energy using natural resources has brought great social and territorial changes: an important and decisive factor was the use of water power in converting food.

The building was constituted by a wheel with shovels (waterwheel) fixed to a shaft (axis) and moved by the water current which gave it a continuous rotary movement; such motion was then forwarded to various types of machinery.

The water was directed onto the wheel by a narrow canal, and its speed was adjusted by the canal lock to increase or reduce the water's flow (Barisani et al., 2005).

Since the energy available in the territory of the Adda river was most the hydraulics, thanks to the Serio Morto channel and to the numerous irrigation ditches, the factories suitable for such purposes were built along these waterway s (Manfredini, 2005).

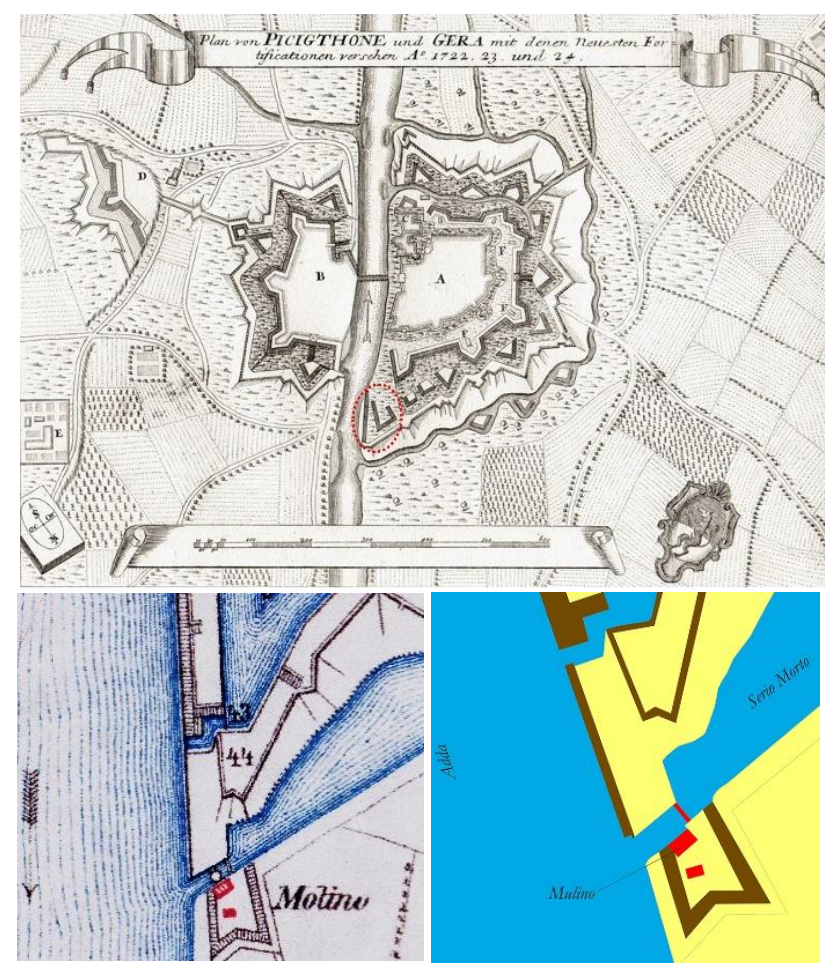

Figure 6. Historical maps of Pizzighettone. Above: map of 1724: in the red circle the area of the mill. Below: map of 1730.

Left: the area of the watermill with the topographic name

"Molino". Right: vectorization and georeferencing of the map.

The historical sources say that in 1796 the French, after the occupation of Pizzighettone, began to work on its fortifications, considered of important strategic value and valid for the storage of the war material. The fortifications were made mainly reusing bricks from the demolition of the castle of Pizzighettone (begun in 1801 and ended in 1863). They started the works digging new channels in order to carry the water of the Serio Morto to the planned new mill.

Unfortunately, these interventions resulted in vain, because in 1799 and again in 1801 the Serio Morto burst its banks.

Later in 1801, the Army Corps of Engineers established the existence of only one mill in the main square of Pizzighettone, so it could not be attacked by the enemy; they ordered the demolition of the watermill "Mulino degli Spalti" on Serio Morto. The destruction of its two wheels was considered necessary in order to permit the rapid discharge of water during floods and to limit the damage to the country side.

The machinery of the demolished mills was mostly reused in the construction of the new factory, called "Mulino del Castello" (Mill of the Castle) whose construction began in 1804 within the area of the fortress (Tansini et al., 2003).

Very interesting is the total correspondence between the ancient and the modern world in exploitation of water: in fact, the channels and mill-wheels of the older times are equal to the channels and turbines in the modern age. Today, the turbine is the technical evolution of the watermills' wheels, once built on the banks of the river to use the water as a driving force to grind. 


\section{SURVEY AND METHODOLOGY}

The project represents an example of topographic emergency survey allowing the complete acquisition and digital reconstruction of the compromised structures at the time of the work that would have been demolished to proceed with the building of the plant.

The fieldwork was carried out through cleaning the area, highlighting the preserved structures and through the photographic and graphic documentation.

The methodology and the software (Agisoft PhotoScan, Qgis, Blender, Gimp) employed were very sustainable during each phase of the work.

The aim of the reality-based and virtual 3D reconstruction is the disclosure of the acquired and processed archaeological data, for the common audience of visitors, considering also the diffusion of the data to valorise the cultural heritage.

The first step of the work was the realization of a photographic coverage of the site, intended to create a detailed map to georeference the few preserved structures of the mill and generating a 3D model through the use of the digital photogrammetry.

This technique of $3 \mathrm{D}$ recording with passive sensors adopts exclusively digital photos to generate accurate $3 \mathrm{D}$ reconstruction of real objects, based on the integration of data acquisition, modelling and representation (Taylor et al., 1996; Manfredini et al., 2010).
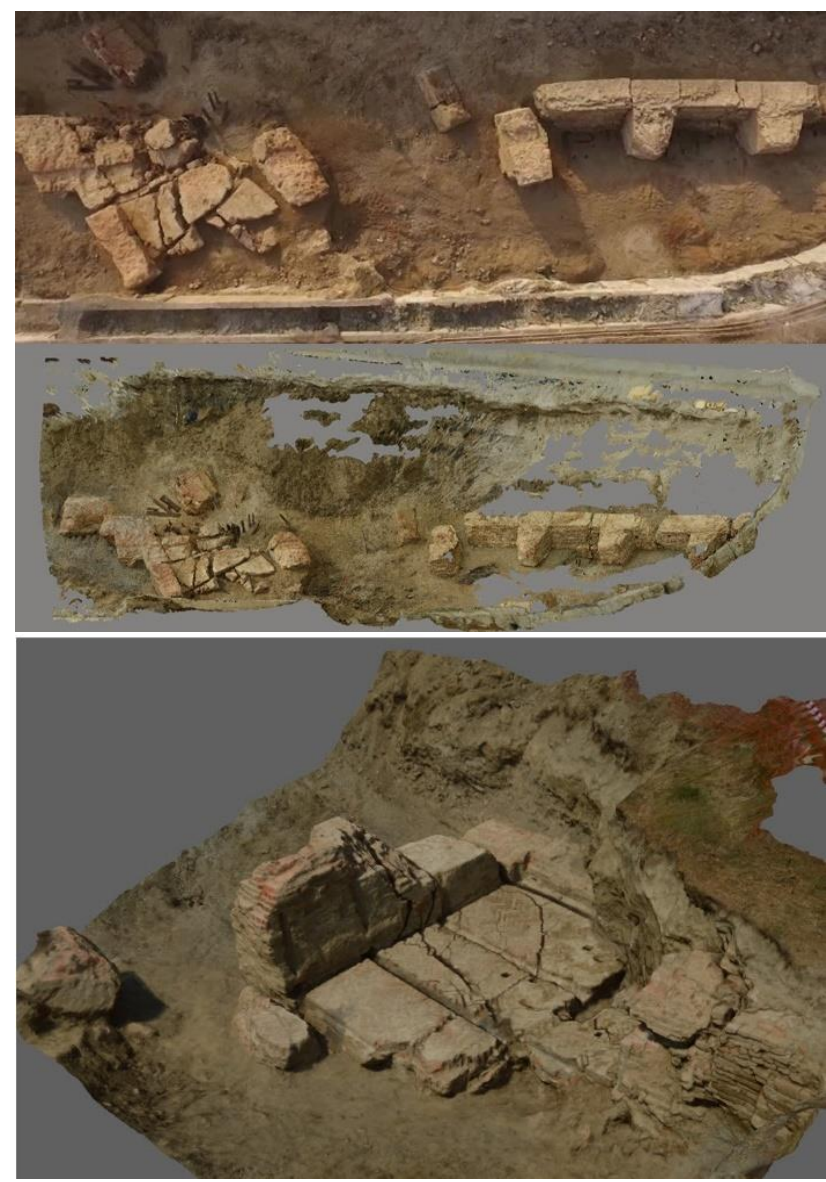

Figure 7. Above: a frame from the drone video of the archaeological structures and the 3D model of the fortified wall and part of the watermill. Below: detail of reality-based 3D model of the channels from close range photogrammetry.
The application of 3D image-based modelling method on this archaeological site, using a simple acquisition hardware (digital camera) and low cost software for data processing, has led to a notable increase in the quality and amount of documentation; moreover, it has also reduced drastically the time and effort during on-site acquisition, processing and visualisation.

Photogrammetry allows the conversion of the photographed environment into a measurable three-dimensional model, with much more details and information than it is possible to obtain with traditional topographic survey. The data accuracy is comparable to that of the $3 \mathrm{D}$ representations obtained from laser scanner (Fassi et al., 2013).

It is an efficient and economical procedure to extract from digital photographs all the essential data such as distances and coordinates. It is possible to reproduce 2D plans, elevations, profiles and other spatial information for the $3 \mathrm{D}$ reconstruction; furthermore, the details and the texture, visually enhanced the created volumes with the photo-realistic quality (Cavada et al., 2010; Russo et al., 2011).

All the acquisitions on site were made with terrestrial photogrammetry, taking advantage of a custom-built structure consisting of a telescopic mast (Blockley et al., 2015).

Some other images were extracted from a video filmed by a drone to document the workings of the hydroelectric plant; the frames of this video, even if done for different purposes, were very useful, once reprocessed, to contextualize the archaeological structures in landscape.

The low cost software Agisoft PhotoScan was used to process the data collected; it employs the structure from motion and automated algorithms for dense stereo matching, to automatically generate 3D models with texture and creates ortophotos. These images were successively imported into AutoCAD to vectorise the structures of the mills and integrated with the field surveys.

The goal of this work was to survey and process the digital data to obtain a 3D virtual reconstruction of the watermill even with feeble evidences and few stratigraphic records.
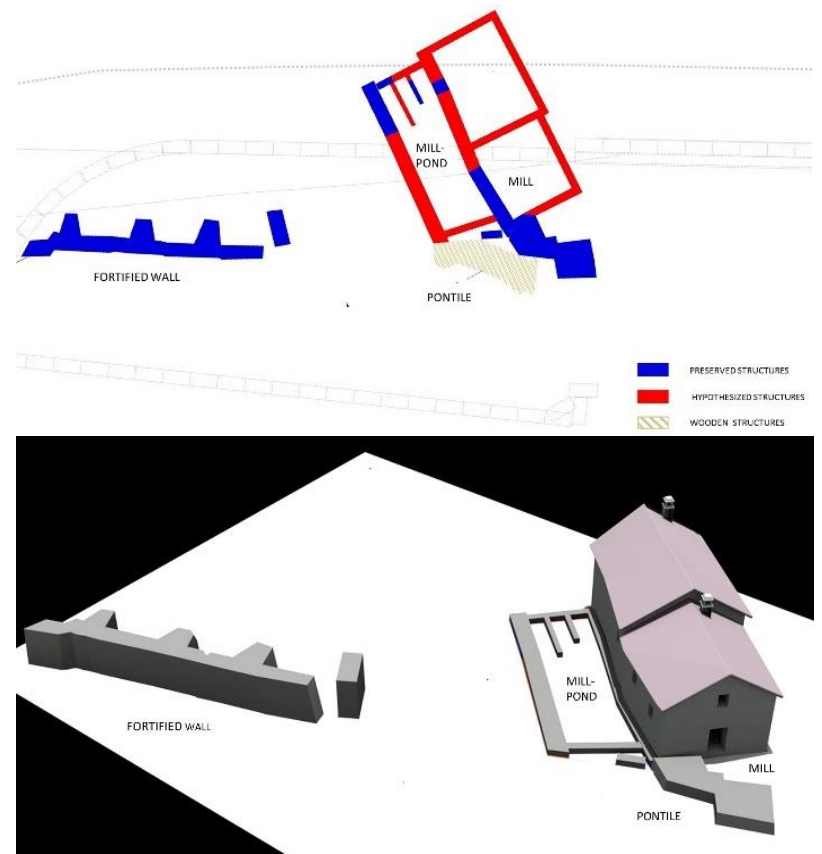

Figure 8. Above: plan of the archaeological remains (blue existent structures, red hypothesized structures, light brown wooden structures). Below: reconstruction of the ancient mill based on the plan obtained from the archaeological survey. 
The 3D model has the advantage of instantly representing the object in its original architecture and entirety, making available the data to general public, helping people to visualize the ancient site and comprehend it better.

The virtual model has various and effective values as historical, scientific, didactic and other, depending on the information that it provides, and it can also be useful to estimate the evolution of the environment quantifying the changes in the area through time (Fassi et al., 2016).

For the 3D remodelling of the watermill the comparison of different sources was used.

The starting point was the archaeological investigation and the data obtained during the fieldwork through photographic and topographic survey, that have been integrated by historical, cartographic, iconographic and oral sources and subsequently processed through 3D graphic.

To create a virtual reconstruction of the elevations of the mill "Mulino degli Spalti" the comparison was made with some of the few examples of post-mediaeval period still preserved in their original form: "Mulino Molinazzo" of Zelo Bonpersico (Lodi) "Mulino Gerette" of San Colombano al Lambro (Milano) e "Mulino San Salvario" in Casalpusterlengo (Lodi).
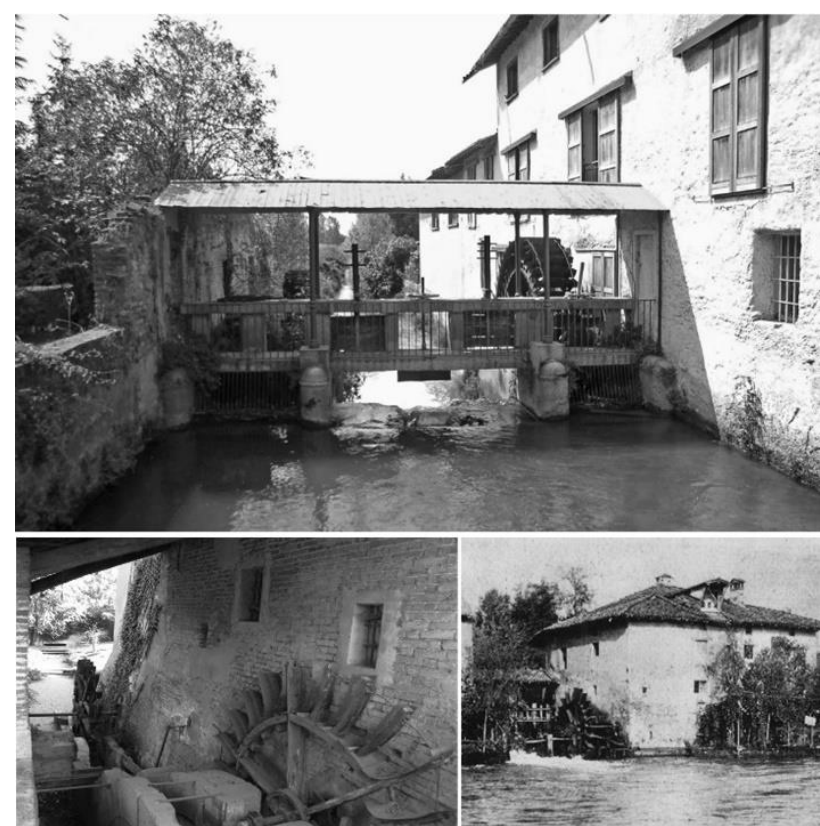

Figure 9. Examples of post-medieval watermill still preserved. Above: Mulino Molinazzo of Zelo Bonpersico (Lodi).

Below: on the left, particular of the waterwheels of Mulino San Salvario in Casalpusterlengo (Lodi); on the right, Mulino

Gerette of San Colombano al Lambro (Milano).

The 3D model was created with the open source software Blender, starting from the vector plan obtained with AutoCAD. The missing part of the structures, as the water channels for the functioning of the wheels and the locks, were realized on the basis of the thickness of the preserved walls and their volumes were obtained with the extrusion and the comparison with the studied or existing structures mentioned above.

Then, on the 3D model were applied textures taken from actual photos of existing mills to enrich it with real-life quality.

The images were firstly elaborated in Gimp then UV mapped in Blender and the textured 3D model was overlaid on the background of the actual landscape.
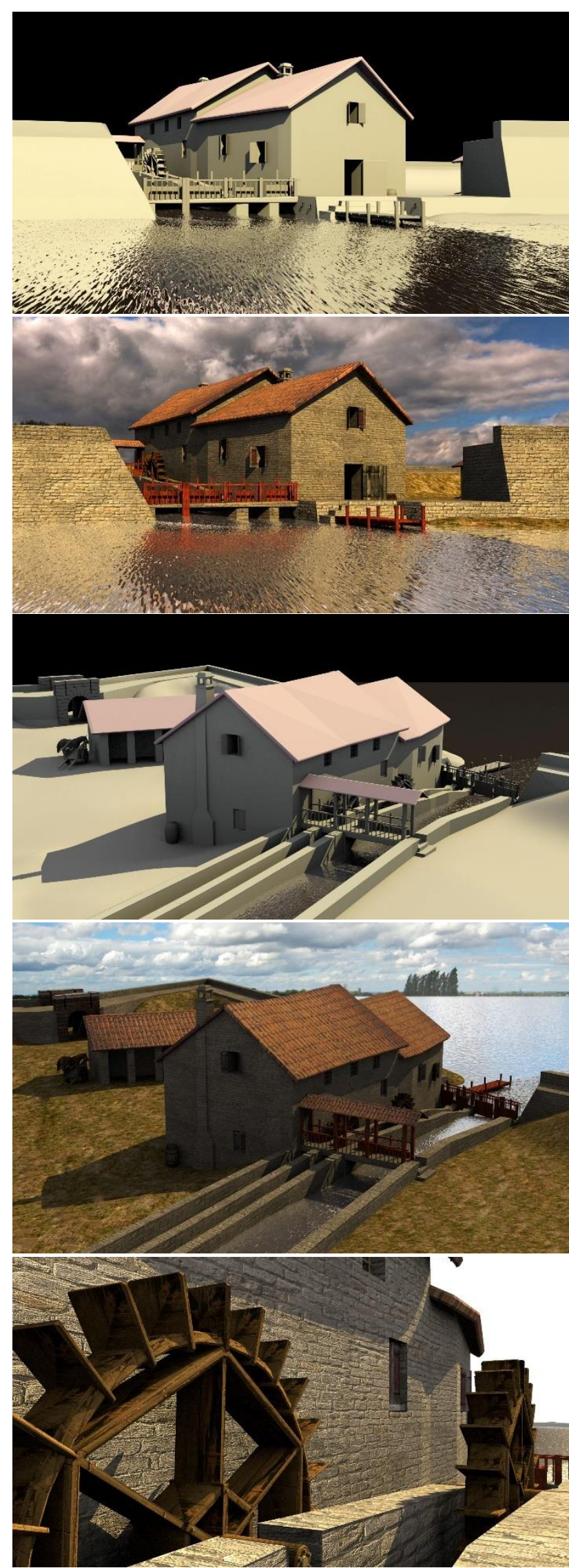

Figure 10. The 3D virtual model of the mill built with Blender: images of the structure without and with textures; general and particulars views 


\section{RESULTS AND FUTURE APPLICATIONS}

The final outcomes of this work, aimed to the divulgation and valorisation of the site, are: a 3D model, a video, a mobile application and some stereoscopic panoramas.

The 3D model of the watermill, as we suppose it was in the XVIII century, is the starting point for different communication solutions that allow visitors to take virtual tours through a video and applications for smartphones and tablets.

A desirable and useful employment of the model is to make it accessible on mobile device; in fact, the $3 \mathrm{D}$ reconstruction permits an immediate and autonomous comprehension of the structure and in the meantime is a great tool for simple inquiry and study on the virtual model (Kurdy et al., 2011).

A video and a mobile application were created; the video describes in few minutes the investigation in Pizzighettone and the workflow of the reconstruction, starting from the topographical position of the watermill, the preserved evidences, the historical and iconographic attestation of the building up to its original aspect with the virtual reconstruction.

It represents a simple document of multimedia information that provides the remote navigation within the 3D model of the site, that could be made available on the website of the Municipality of Pizzighettone.

The application is based on AR that overlays real-time data with VR, providing a better involvement in the comprehension of the post-mediaeval disappeared mill and giving people the opportunity of a virtual visit of the structure from a video screen (Milgram et al., 1994; Morandi, 2016).

Two custom markers were created for the 3D rendering: one of remains of the mill, the other of the reconstruction of the ancient structure. These markers can be identified by the proprietary software and they reproduce the photorealistic, virtual threedimensional model in AR environment.
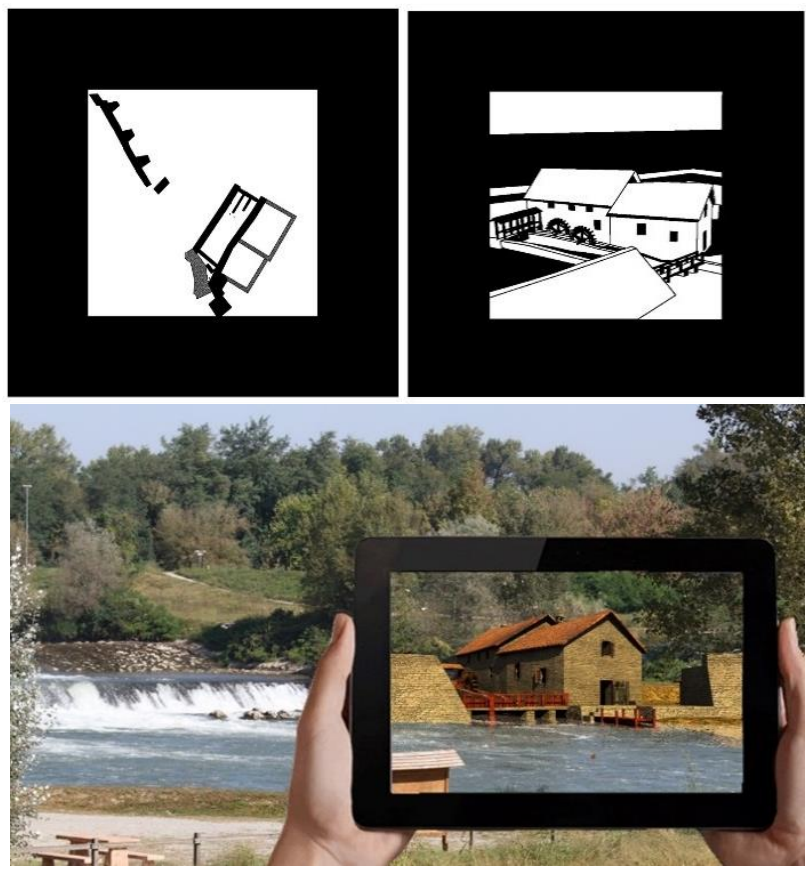

Figure 11. Above: two custom markers for the rendering of the $3 \mathrm{D}$ reconstruction visible and navigable in AR. Below: on site use of AR system.
The 3D models realized have been also merged into a 3D PDF, an interactive digital publication system with models that can be explored, interrogated and easily downloaded scanning a QR code with smartphones or tablets through the connection with the Municipality's website (Fiorini, 2012).

Some panels with these downloadable multimedia contributions would be installed directly in the area of the new plant on the bank of the Adda river. In this way, it will be possible the virtual access to the archaeological asset removed due to the construction of the plant; besides some monitors and multimedia devices will be installed in the local museum for video streaming.

The stereoscopic panoramas, pervasive technologies to show the $3 \mathrm{D}$ models in a lightweight and smart way, that represent $360^{\circ}$ views of the virtual reconstructions, were employed in this case study.

In order to provide a panoramic view of nowadays area, some $360^{\circ}$ images of the hydroelectric plant were acquired with the panoramic camera Ricoh Theta and were stitched together with the proprietary software and a virtual tour of the construction site was created with Kolor Pano Tour.

Moreover, the tour will be elaborated including the virtual reconstruction of the mill and the environment, so it will be possible to have some panoramic views of the area as it was in the past.

In this case, the virtual tour is going to be published to use it with a simple virtual reality Head Mounted Display (HDM) and an application for smartphone giving an immersive experience; the system employs the stereoscopy to give the illusion of depth (Fabola, 2016; Morandi et al., 2016).

With this method, we intend to allow a virtual tour of the area, displaying the $3 \mathrm{D}$ reconstruction of the watermill that permits people who pass close to the bank of Adda, to take a virtual tour understanding how the landscape has transformed: where today people see a hydropower plant, once there was a mill that exploited the force of Adda waters for energy production.

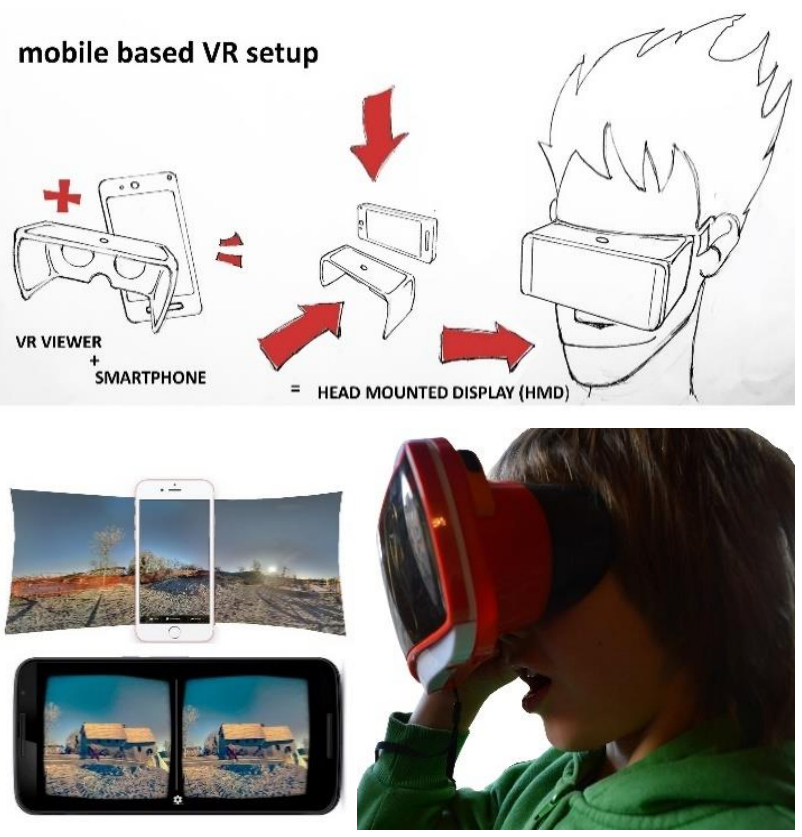

Figure 12. Above: explanation of the mobile based VR setup. Below: on the left, $360^{\circ}$ panoramic view of the area and 3D model navigable in VR; on the right, the head mounted display for VR. 


\section{CONCLUSIONS}

The purpose of the research is to prove the potentials offered by modern digital technologies, mainly the image-based modelling and the virtual archaeology, to study, protect and communicate the archaeological sites that are daily subjected to frequent emergency interventions in the whole Italian territory.

The application of digital photogrammetry and the virtual reconstruction of Pizzighettone watermill was particularly interesting and efficacious; considering that, at the time of the survey, no documentation was available and it was necessary to immediately remove the archaeological remains to allow the construction of the plant. After only a few days of survey and elaboration of data, 2D and 3D graphic documentation of the whole archaeological area was obtained, useful both for scientific and informative purposes.

The 3D model of the watermill, realized as we presume it was in the XVIII century, proved to be an effective tool for the dissemination of archaeological data.

The combination of mobile devices with 3D models managed by AR e VR technologies provides numerous opportunities in the field of investigation, preservation and communication, increasing our understanding of the landscape, simplifying onsite exploration of heritage environments and enhancing the "minor" archaeological sites, daily subjected to numerous emergency work.

Everyday archaeological remains are discovered during urban works; excavations consistently produce vast amounts of data that are often confined to the archives of the superintendence and therefore not accessible to the public.

The case study presented here allows to follow a model to valorise, through the use of low cost and non-invasive technologies, an immense amount of usually invisible archaeological assets.

The interactive products potentially increase the divulgation and visualisation for the general public, in the belief that the preservation and protection of the "minor" archaeological heritage is possible only through knowledge and the disclosure.

\section{ACKNOWLEDGEMENTS}

Thanks are due to Dr. Nicoletta Cecchini and Dr. Andrea of Lombardy's Superintendence for Archaeological Heritage, who oversaw the entire project, and Edison S.p.A. and Studio Ar.Te (Archeologia e Territorio) for the logistic support during the fieldwork, the survey and the data processing.

\section{REFERENCES}

Barisani, A., Piccolo, M., Ruggeri, L., 2005. Mulini suggestioni di un mondo perduto, Cremona Produce (Eds); Cremona.

Blockley, P., Morandi, S., 2015. The recording of two late roman towers, Archaeological Museum. 3D documentation and study using image-based modelling, in Digital Heritage 2nd International Congress, Granada, (DH15), Vol. 1 pp. 103 106.

Cavada, E., Rapanà, M., 2010. Ruderi riletti: approccio e problemi di modellazione tridimensionale. Archeologia e Calcolatori, 21, pp. 145-165.
Fabola, A., Miller, A., 2016. Exploring the past with Google Cardboard, in Digital Heritage 2nd International Congress, Granada, (DH15) Vol. 1, pp.277-284.

Fassi, F., Fregonese, L., Ackermann, S., De Troia, V., 2013. Comparison between laser scanning and automated 3D modelling techniques to reconstruct complex and extensive cultural heritage areas. ISPRS Workshop 3D-ARCH: 3D virtual reconstruction and visualization of complex architectures, Trento, pp.73-80.

Fassi, F., Mandelli, A., Teruggi, S., Rechichi, F., Fiorillo, F., Achille, C., 2016. VR for Cultural Heritage. A VR-Web-BIM For The Future Maintenance Of Milan's Cathedral, Salento AVR16.

Fiorini, A., 2012. Tablet Pc, fotogrammetria e pdf 3D: strumenti per documentare l'archeologia. Archeologia e Calcolatori, 23, pp. 213-227.

Kurdy, M., Biscop, J.L., De Luca, L., Florenzano, M., 2011. 3D virtual anasty losis and reconstruction of several buildings in the site of Saint-Simeon, Syria, International Archives of the Photogrammetry. Remote Sensing and Spatial Information Sciences Vol. XXXVIII-5/W16 ISPRS, pp.45-52.

Manfredini, A.M., Remondino, F., 2010. Modellazione 3D da Immagini. Pipeline Fotogrammetrica, in Modelli Digitali 3D: il Caso Di Pompei, Benedetti, Gaiani, Remodino (a cura di), pp.162-199, Edizioni della Normale (Eds), Pisa.

Manfredini, G., 2005. Mulini, Mulini da grano, pile da riso, torch da olio. Ricognizione del patrimonio edilizio, Settore territorio Provincia di Cremona (Eds), Cremona.

Milgram, P., Kishino, F., 1994. A taxonomy of mixed reality visual displays in IEICE, Transactions on Information Systems (Special Isuue on Networked Reality), Vol. E77-D, 12, pp.13211329.

Morandi, S., 2016, 3D documentation ad study of a medieval site using image-based modelling: Bastia S. Michele (Cavaion Veronese, VR; Italy), Proceedings of MetroArcheo 2015, 1st International Conference on Metrology for Archaeology, Benevento, pp. 467-471.

Morandi, S., Tremari, M. 2016. Make the invisible visible. Virtual reconstruction of a submerged medieval church (S.Siro; Como, Italy) $22^{\text {nd }}$ International Conference on Virtual Systems and Multimedia (VSMM 16) Kuala Lumpur, (in press).

Russo, M., Remondino F., Guidi, G., 2011. Principali tecniche e strumenti per il rilievo tridimensionale in ambito archeologico. Archeologia e Calcolatori, 22, pp.169-198.

Tansini, D., Gambarelli, G., 2003. Pizzighettone e Gera: un borgo, il suo fiume e la sua gente, Cremona.

Taylor, C.J., Devebec, P., Malik, J., 1996. Reconstructing polyhedral models of architectural scenes from photographs. Proceedings of the European Conference on Computer Vision (ECCV96), pp.659-668. 